\title{
Analyses of association between PPAR gamma and EPHX1 polymorphisms and susceptibility to COPD in a Hungarian cohort, a case-control study
}

\author{
Andras Penyige ${ }^{1 * \dagger}$, Szilard Poliska ${ }^{2,3 \dagger}$, Eszter Csanky $^{5,9}$, Beata Scholtz ${ }^{3}$, Balazs Dezso ${ }^{6}$, Ivan Schmelczer ${ }^{1}$, lain Kilty ${ }^{7}$, \\ Laszlo Takacs ${ }^{8}$, Laszlo Nagy ${ }^{2,3,4^{*}}$
}

\begin{abstract}
Background: In addition to smoking, genetic predisposition is believed to play a major role in the pathogenesis of chronic obstructive pulmonary disease (COPD). Genetic association studies of new candidate genes in COPD may lead to improved understanding of the pathogenesis of the disease.

Methods: Two proposed casual single nucleotide polymorphisms (SNP) (rs1051740, rs2234922) in microsomal epoxide hydrolase (EPHX1) and three SNPs (rs1801282, rs1800571, rs3856806) in peroxisome proliferator-activated receptor gamma (PPARG), a new candidate gene, were genotyped in a case-control study (272 COPD patients and 301 controls subjects) in Hungary. Allele frequencies and genotype distributions were compared between the two cohorts and trend test was also used to evaluate association between SNPs and COPD. To estimate the strength of association, odds ratios (OR) (with 95\% Cl) were calculated and potential confounding variables were tested in logistic regression analysis. Association between haplotypes and COPD outcome was also assessed.

Results: The distribution of imputed EPHX1 phenotypes was significantly different between the COPD and the control group $(P=0.041)$, OR for the slow activity phenotype was $1.639(95 \% \mathrm{Cl}=1.08-2.49 ; \mathrm{P}=0.021)$ in our study. In logistic regression analysis adjusted for both variants, also age and pack-year, the rare allele of His447His of PPARG showed significant association with COPD outcome $(\mathrm{OR}=1.853,95 \% \mathrm{Cl}=1.09-3.14, \mathrm{P}=0.0218)$. In haplotype analysis the $\mathrm{GC}$ haplotype of PPARG $(\mathrm{OR}=0.512,95 \% \mathrm{Cl}=0.27-0.96, \mathrm{P}=0.035)$ conferred reduced risk for COPD.

Conclusions: The "slow" activity-associated genotypes of EPHX1 were associated with increased risk of COPD. The minor His447His allele of PPARG significantly increased; and the haplotype containing the minor Pro12Ala and the major His447His polymorphisms of PPARG decreased the risk of COPD.
\end{abstract}

\section{Background}

Chronic obstructive pulmonary disease (COPD) is an increasing and serious public health problem representing the fourth leading cause of death globally. COPD is a complex human disease, associated with persistent airway inflammation, protease-anti-protease imbalance, oxidative stress, chronic obstructive bronchitis and

\footnotetext{
* Correspondence: penyige@med.unideb.hu; nagyl@med.unideb.hu

+ Contributed equally

'Department of Human Genetics, University of Debrecen, Debrecen, Hungary

${ }^{2}$ Department of Biochemistry and Molecular Biology, Research Center for

Molecular Medicine, University of Debrecen, Debrecen, Hungary

Full list of author information is available at the end of the article
}

emphysema, resulting in progressive airflow limitation that is not substantially reversed by bronchodilators. Importantly, it is a smoking-related disorder and cigarette smoking is the major environmental risk factor for development of COPD. However, the fact that only a subset of smokers (15-20\%) develops clinically significant symptoms suggests that genetic predisposition also plays role in the development of COPD [1,2].

Previous genetic association and genome-wide linkage studies have identified several candidate genes that might be involved in the pathogenesis of COPD [3-7].

In our case-control study, five putative causal single nucleotide polymorphisms (SNPs) in two genes - 
microsomal epoxide hydrolase $(E P H X 1)$ and peroxisome proliferator-activated receptor gamma (PPARG) - were chosen to analyze their association with COPD.

PPARG is a member of nuclear hormone receptors, implicated in adipocyte differentiation and involved in macrophage activation and dendritic cell biology [8]. An anti-inflammatory role of PPARG was also reported based on its inhibitory effect on pro-inflammatory transcription factors such as NF- $\kappa \mathrm{B}$ and AP-1 $[9,10]$. The NCBI SNP database features more than 700 polymorphisms of PPARG, many of them intronic or synonymous variant and generally lack of information regarding population diversity.

Several studies on the polymorphisms of PPARG such as Pro12Ala and His447His were previously performed in relation to inflammatory diseases such as IBD, type 2 diabetes and recently it has been suggested that PPARG polymorphisms were associated with the risk of asthma [11]. Since PPARG might be involved in the regulation of pro-inflammatory signaling pathways and it is generally accepted that COPD is associated with an abnormal inflammatory response, genetic polymorphisms in PPARG could be implicated in the susceptibility to COPD risk [12]. That may provide a theoretical basis for the study of this new candidate gene in COPD development. Consequently, we examined the association between three SNP polymorphisms of PPARG gene and COPD.

$E P H X 1$ is an enzyme associated with the metabolism and detoxification of xenobiotic chemicals; it plays an important role in the general oxidative defense of lung. Several polymorphisms are known in EPHX1 including two relatively common SNPs, the exon 3 Tyr113His (rs1051740) and exon 4 His139Arg (rs2234922) variants. These two variant alleles have been suggested to be associated with altered EPHX1 enzyme activity [13]. Substitution of Tyr113 for His decreases EPHX1 activity (slow allele), whereas substitution of His139 for Arg increases $E P H X 1$ activity (fast allele). It was found that the slow metabolizing form of EPHX1 was associated with an increased risk for COPD and evidence supporting this association has been replicated in several casecontrol genetic association studies $[7,14,15]$. However, the evidence supporting this association has not been consistent, several genetic association studies failed to show association between these polymorphisms and COPD [16,17]. In this study we have chosen the Tyr113His and His139Arg polymorphisms to validate our Hungarian population for COPD association studies.

All together a total of five SNPs in two candidate genes were genotyped in order to examine their association with COPD susceptibility by using Hungarian cohorts, a previously uninvestigated population with the highest COPD mortality rate among men in Europe [18].

\section{Methods \\ Study populations}

The study is a case-control genetic association study in a Central-European Caucasian population. In our analysis the cases included 272 and the control subjects included 301 age-matched Hungarian individuals. The recruitment and the clinical analyses of patients were conducted at the Department of Pulmonology, Medical and Health Science Center, University of Debrecen, according to the Global Initiative for Chronic Obstructive Lung Disease (GOLD) criteria. The Research Ethics Committee of University of Debrecen Medical and Health Science Center approved the clinical protocol and the study. Written informed consent was obtained before the subjects entered the study. The investigator explained the nature, purpose and risk of the study and provided the subject with a copy of the information sheet. The subjects were then given time to consider the study's implication before deciding to participate.

Before starting sample collection, we defined inclusion and exclusion criteria of diseased and healthy patients. Inclusion criteria for COPD subjects were age 40 to 65 years old. Patients must have predicted value of forced expiratory volume at 1 second (FEV1) $50 \%-80 \%$ and FEV1/FVC\% $<70 \%$ (stage 2 according to GOLD criteria). Inclusion criteria for control patients were age between 40 and 65 years; normal spirometry, FEV1 $\geq 90 \%$ (predicted value) and FEV1/FVC\% $\geq 80 \%$. All patients must be current or ex-smoker (minimum 15 pack years).

Exclusion criteria for all patients: plasma IgE level $>70$ $\mathrm{U} / \mathrm{ml}$, alpha1-antripsin deficiency, evidence of asthma, atopic disease, history of lung disorders, respiratory infection in the past 3 months, other inflammatory diseases (e.g. inflammatory bowel disease, rheumatoid arthritis, psoriasis etc.), autoimmune diseases (lupus, sclerosis), cancer, positive plasma test for HIV, Hepatitis B or Hepatitis C.

\section{Genotyping}

Genomic DNA was extracted from peripheral blood using E.Z.N.A. Blood DNA Midi Kit (Peqlab Biotechnologie) according to the manufacturer's protocol. Quality of the DNA samples was checked by agarose gelelectrophoresis and quantitated by NanoDrop1000. All SNPs were genotyped using TaqMan genotyping assays (Additional File 1, Table S1). Samples were measured in duplicates and nuclease-free water was used as notemplate control. Following PCR amplification the endpoint fluorescence was read with the ABI $7900 \mathrm{HT}$ instrument and genotypes were assigned using SDS 
software (Applied Biosystems). The average genotyping success rate of at least 95\% was attained for each SNP.

\section{Alveolar macrophage (AM) and peripheral blood monocyte (MO) collection}

Bronchoalveolar lavage fluid (BALF) samples were collected by fiber-optic bronchoscopy from healthy and COPD patients. AMs were separated by Percoll (Amersham Biosciences) gradient centrifugation. Total cell number was determined by counting in hemocytometer. Differential cell count was assessed on hematoxylineosin stained cytospin slides before and after the gradient separation. Over 95\% AM purity was reached after separation.

$50 \mathrm{ml}$ heparin treated venous blood was collected from healthy and diseased patients. MOs were separated by Ficoll gradient centrifugation using anti-CD14 conjugated microbeads (>98\% MO) (VarioMACS, Miltenyi Biotec.). 5-5 control and COPD patients were recruited in this experiment.

\section{TaqMan RT-QPCR}

Total RNA was isolated from peripheral blood monocytes, alveolar macrophages, lung tissue and adipose tissue using Trizol reagent (Invitrogen). First strand cDNA was generated from 5 ug total RNA using cDNA Archive Kit (Applied Biosystems). For RT-QPCR reaction $200 \mathrm{ng}$ cDNA/sample and 2X TaqMan PCR mix (Applied Biosystems) was used. Reactions were run in ABI Prism HT 7900 instrument. We have designed primer pair and probe for measuring PPARG mRNA level. Forward primer: 5'GATGACAGCGACTTGGCAA, reverse primer: 5'CTTCAATGGGCTTCACATTCA, probe: 5'FAM-CAAACCTGGGCGGTCTCCACTGAG3'TAMRA. The housekeeping gene cyclophilin A was used as a normalizer gene: forward primer: 5'ACGGCGAGCCCTTGG, reverse primer: 5' TTTCTGCTG TCTTTGGGACCT, probe: 5'FAM-CGCGTCTCC TTTGAGCTGTTTGCA-3'TAMRA. Relative gene expression levels were calculated by comparative $\mathrm{Ct}$ method. Statistical analysis was performed in GraphPad Prism using non-parametric test (Mann-Whitney U-test).

\section{Immunohistochemistry}

Tissues for morphology and immunostainings were obtained from the files of the Pathology Department of University of Debrecen and were freshly fixed in $10 \%$ neutral formalin and embedded in paraffin followed by hematoxyline and eosine (HE) staining using standard methods. Immunohistochemistry (IHC) for alveolar macrophages (AM) was carried out using PPARG, CD68 and DCSign (Santa Cruz) monoclonal antibodies by means of immunoperoxidase staining as described earlier $[19,20]$. Double immunofluorescence staining was performed as described earlier [21] using CSAII detection kit with FITC-labeled tyramine followed by an immunofluorescent staining for DCSign with streptavidin-texas red fluorochrome. Nuclear counterstaining was made with DAPI (blue fluorescence).

\section{Statistical analysis}

Differences between cases and the control group concerning demographic and main clinical data were analyzed by Mann-Whitney $U$-test and Pearson $\chi^{2}$ test. Genotype data for each SNP were tested for departures from Hardy-Weinberg equilibrium (HWE) separately in case and control populations using a goodness-of-fit $\chi^{2}$-test or the exact test to estimate $P$ values. HWE calculations were done by using the HWE tool http://ihg. gsf.de/cgi-bin/hw/hwa1.pl. The significance of differences in genotype and allele frequencies between patients and controls were tested by using either $\chi^{2}$ analyses or Fisher's exact test where appropriate [22]. To assess the degree of association between each of the SNPs and COPD odds ratios with $95 \%$ confidence intervals (OR, 95\% CI) were calculated using logistic regression analysis; the model was adjusted for SNPs, packyear, age and gender. All single locus association tests were performed using the STATA 9.0 statistical package (except where otherwise stated).

Haplotype frequencies were estimated for control and patient groups separately with the Full-Precise-Iteration algorithm implemented in the SHEsis software http:// analysis.bio-x.cn/myAnalysis.php. The extent of linkage disequilibrium between pairs of biallelic markers was determined using both the standardized disequilibrium and correlation coefficients (given as Lewontin's D' and $\mathrm{r}^{2}$, respectively) and association between haplotypes and COPD was assessed by the $\chi^{2}$-test or the exact test as implemented in the program SHEesis [23,24]. Correction for multiple testing was not used in the analysis of the association genotype and allele frequencies because: (i) the EPHX1 polymorphisms were known to be functional and (ii) the gene is considered a susceptibility gene for COPD; and (iii) in case of the PPARG polymorphisms the studied individual alleles were not independent. A posteriori estimates of study power were assessed by means of Quanto software http://hydra.usc. edu. We have estimated the power of our study with the following parameters: sample size of 272 cases; control/ case ratio of 1.1; minor allele frequencies (MAF) are in the range from 0.12 to 0.3 ; log-additive model; disease prevalence of COPD 5\%. Assuming these parameters our study had $\sim 50 \%$ power to detect a genotype relative risk (GRR) of 1.4 for MAF $=0.12$, or $\sim 79 \%$ power to detect a GRR of 1.6 for the same MAF; while it had $\sim 76 \%$ power to detect a GRR of 1.4 , and $\sim 96 \%$ power to 
detect a GRR of 1.6 for MAF $=0.3$ at an $\alpha=0.05$ significance level.

\section{Results}

Of the 573 subjects genotyped, $61.8 \%$ of the subjects were men. The proportion of males was higher among cases $(69.85 \%$ to $54.48 \%)$ but there is no significant difference in the mean age of controls and cases. Cases had been exposed to more tobacco smoke as evidenced by the difference in pack-years but the difference is not significant, COPD patients had a much larger reduction in lung function, typical for a clinical COPD population (Table 1).

All genotype frequencies were consistent with HardyWeinberg equilibrium for both SNPs of the EPHX1 gene, and the genotype and allele frequencies did not differ significantly between cases and the control group (Table 2). The assessment of the association of individual SNPs with COPD showed that homozygosity for the minor allele increased the risk of disease in case of Tyr113His polymorphism ("slow" allele) $(\mathrm{OR}=1.345$; $95 \% \mathrm{CI}=0.96-1.91 ; \mathrm{P}=0.095)$ reduced it in case of the His139Arg SNP ("fast" allele) $(\mathrm{OR}=0.675 ; 95 \% \mathrm{CI}=$ 0.27 - 1.69; $\mathrm{P}=0.399)$. However, none of these SNPs were significantly associated with COPD even after adjusting the model for gender, age and pack-years in logistic regression.

Frequencies for the four SNP based haplotypes were estimated for cases and controls. Although the "slow activity" CA (His ${ }^{113}$-His ${ }^{139}$ ) haplotype was more frequent among cases (24.8\% versus the $20.8 \%$ in controls), the overall distribution did not differ significantly between the two groups $(P=0.736)$. Furthermore, alleles of the two loci in EPHX1 are in complete linkage equilibrium as shown by the pair-wise standardized disequilibrium coefficient $\left(D^{\prime}=0.036\right.$ ).

Due to the presence of these coding variants, marked variations in EPHX1 activity have been reported previously. Therefore we have assessed the association of the predicted (rapid", "normal", "slow" and "very slow") $E P H X 1$ phenotypes with the development of COPD

Table 1 Clinical features of the study population

\begin{tabular}{llll}
\hline Parameter & $\begin{array}{l}\text { Cases } \\
\mathbf{( N ~ = ~ 2 7 2 ) ~}\end{array}$ & $\begin{array}{l}\text { Controls } \\
\mathbf{( N = 3 0 1 )}\end{array}$ & P value \\
\hline Male $(\%)$ & $190(69.85)$ & $164(54.48)$ & 0.781 \\
\hline Age $( \pm S D)^{*}$ & $63.87( \pm 8.96)$ & $64.29( \pm 9.07)$ & 0.577 \\
\hline Pack-Years $( \pm S D)^{*}$ & $38.75( \pm 19.91)$ & $34.76( \pm 14.71)$ & 0.120 \\
\hline FEV1\% predicted $( \pm S D)^{*}$ & $47.17( \pm 13.69)$ & $99.28( \pm 9.76)$ & $<0.0001$ \\
\hline FEV1/FVC\% predicted $( \pm S D) *$ & $57.57( \pm 10.12)$ & $87.10( \pm 35.24)$ & $<0.001$
\end{tabular}

Data presented as mean \pm SD. FEV1: forced expiratory volume in one second, FVC: forced vital capacity, *Mann-Whitney U-test was used.
$[25,26]$. The distribution of predicted $E P H X 1$ activity was significantly different between control subjects and COPD patients $(\mathrm{P}=0.041)$. In the analysis of predicted phenotypes the COPD group had higher proportion of the predicted "slow" phenotype. Consequently the slow phenotype significantly raises the risk of developing COPD $[\mathrm{OR}=1.639 ; 95 \% \mathrm{CI}=1.06-2.49 ; \mathrm{P}=0.021)]$ in our case control study (Table 3 ).

High expression level of PPARG mRNA in the lung has been reported previously $[27,28]$. We examined $P P A R G$ expression at protein level in surgical lung tissue samples. PPARG protein is expressed in the lung and most of the PPARG protein derived signals co-localized with the expression of a typical macrophage marker CD68 and the dendritic cell marker DCSign (Figure 1). PPARG expression was also measured at mRNA level. mRNA expression is enriched in AM relative to total lung tissue, however we did not find differences in expression level between COPD and healthy individuals (Figure 2). Thus, genetic variants, rather than the expression of the PPARG gene could be associated with the development of COPD.

We have genotyped three exonic SNPs (rs10801282 (Pro12Ala), rs3856806 (His447His) and rs 1800571 (Pro113Gln)) in PPARG gene, but the rs 1800571 locus was left out from the analysis because it was homozygous for the major $C$ allele in all individuals. The other two SNPs were in HWE and showed linkage disequilibrium, the extent of LD between rs10801282 and $r s 3856806$ was found to be $D^{\prime}=0.673$, although the pair showed lower LD with respect to their correlation coefficient $\left(r^{2}=0.42\right)$.

The single loci allelic and genotypic analysis found no significant association between the two coding variants of PPARG and COPD. In logistic regression applying a model adjusted for both SNPs, age and pack-years, the rare variant of His447His polymorphism was significantly associated with increased odds for $\operatorname{COPD}(\mathrm{OR}=1.853,95 \% \mathrm{CI}=1.09-3.14, \mathrm{P}=$ 0.021). The minor Ala allele of the Pro12Ala variant had an OR of 0.679 , suggesting a protective effect, however it did not reach significance $(95 \% \mathrm{CI}=0.40$ 1.14, $\mathrm{P}=0.145$ ) (Table 4).

We have estimated the frequency of the possible two-SNP haplotypes of PPARG and assessed the association between haplotypes and COPD development. There was a significant difference in the frequency of the GC haplotype involving the rare $G$ variant of the Pro12Ala locus between the two groups $(P=0.035)$. The strength of association was also assessed, for this haplotype $(\mathrm{OR}=0.512 ; 95 \% \mathrm{CI}=0.27-0.96)$. This finding suggests a protective effect for the GC (12Ala/ $447 \mathrm{His}$ ) haplotype of the PPARG gene for COPD outcome (Table 5). 
Table 2 Allele and genotype frequencies of examined EPHX1 gene polymorphisms

\begin{tabular}{|c|c|c|c|c|c|c|c|c|}
\hline \multirow[t]{2}{*}{ Gene Symbol } & \multirow{2}{*}{$\begin{array}{c}\text { SNP ID } \\
\text { rs1051740 (Tyr113His) }\end{array}$} & \multicolumn{2}{|c|}{ Allele frequency } & \multicolumn{3}{|c|}{ Genotype frequency } & \multirow{2}{*}{$\begin{array}{c}{ }^{5} \text { Hardy-Weinberg Equilibrium } \\
\text { P value }\end{array}$} & \multirow[t]{2}{*}{ OR $(95 \% \mathrm{Cl})$} \\
\hline & & $T$ & C & Tा (\%) & TC (\%) & CC (\%) & & \\
\hline Controls & & 0.723 & 0.277 & $154(53.3)$ & $110(38.1$ & $25(8.7)$ & 0.401 & $1.11(0.86-1.44)$ \\
\hline \multirow[t]{2}{*}{ Cases } & & 0.701 & 0.299 & $127(47.4)$ & $122(45.5)$ & $19(7.1)$ & 0.154 & \\
\hline & rs2234922 (His139Arg) & $A$ & G & AA (\%) & AG (\%) & GG (\%) & & \\
\hline Controls & & 0.779 & 0.221 & $171(60.0)$ & $102(35.8)$ & $12(4.2)$ & 0.507 & $0.88(0.66-1.18)$ \\
\hline Cases & & 0.799 & 0.201 & $169(62.8)$ & $92(64.2)$ & $8(2.9)$ & 0.280 & \\
\hline
\end{tabular}

${ }^{s} \chi^{2}$-test was used, OR: odds ratio, Cl: confidence interval

\section{Discussion}

The aims of this study were to investigate association of $E P H X 1$ polymorphisms to COPD in a Hungarian population and to assess possible association between SNPs of PPARG, a new candidate gene, and COPD outcome.

In our study of individual SNPs in EPHX1 (the exon-3 Tyr113His and exon-4 His139Arg variants), the homozygous minor Thr113His variant showed only a borderline association with the COPD phenotype ( $P=0.095)$, however the level of association was further reduced when the model was adjusted for age, sex and pack-years.

There is complete linkage equilibrium between Tyr113His and His139Arg SNPs and no statistical significance was found in haplotype frequency distribution and their association with COPD phenotype.

Since EPHX1 is involved in the detoxification of epoxide intermediates in tobacco smoke, the rate of conversion of these highly reactive compounds could affect an individual's ability to cope with the toxic effect of cigarette smoke [29]. We have reconstructed the frequency of predicted $E P H X 1$ activity in patient and control groups $[25,26]$. The difference in distribution of predicted phenotypes was significant between the two groups. The COPD group had a higher proportion of predicted slow and lower proportion of predicted normal and rapid

Table 3 The distribution of the predicted EPHX1 phenotypes

\begin{tabular}{|c|c|c|c|c|c|}
\hline $\begin{array}{c}\text { Predicted } \\
\text { EPHX1 } \\
\text { activity }\end{array}$ & $\begin{array}{c}\text { Controls } \\
\text { n (\%) }\end{array}$ & $\begin{array}{l}\text { Cases } \\
\text { n (\%) }\end{array}$ & $\begin{array}{c}{ }^{\S} \mathrm{P} \\
\text { value }\end{array}$ & $\begin{array}{c}\text { Contingency } \\
\text { tables } \\
\text { OR }(95 \% \mathrm{CI})\end{array}$ & $\begin{array}{c}P \\
\text { value }\end{array}$ \\
\hline Normal & $\begin{array}{c}144 \\
(53.1)\end{array}$ & $\begin{array}{c}123 \\
(48.4)\end{array}$ & & 1 (reference) & \\
\hline Slow & $\begin{array}{c}55 \\
(20.2) \\
\end{array}$ & $\begin{array}{c}77 \\
(30.3)\end{array}$ & & $\begin{array}{c}1.64 \\
(1.08-2.49) \\
\end{array}$ & 0.021 \\
\hline Very slow & $\begin{array}{c}17 \\
(6.2)\end{array}$ & $\begin{array}{c}9 \\
(3.5)\end{array}$ & 0.041 & $0.62(0.27-1.44)$ & 0.306 \\
\hline Rapid & $\begin{array}{c}55 \\
(20.2)\end{array}$ & $\begin{array}{c}45 \\
(17.7)\end{array}$ & & $0.96(0.59-3.19)$ & 0.855 \\
\hline
\end{tabular}

Normal: exon3 Tyr/Tyr and exon $4 \mathrm{His} / \mathrm{His}$ or exon $3 \mathrm{Tyr} / \mathrm{His}$ and exon $4 \mathrm{His} /$ Arg; Slow: exon 3 Tyr/Tyr and exon $4 \mathrm{His} / \mathrm{His}$; Very slow: exon $3 \mathrm{His} / \mathrm{His}$ and exon $4 \mathrm{His} / \mathrm{His}$; Rapid: exon 3 tyr/Tyr and exon $4 \mathrm{Arg} / \mathrm{Arg}$ or His/Arg

${ }^{s} \chi^{2}$-test was used for the distribution of predicted phenotypes, OR: odds ratio, $\mathrm{Cl}$ : confidence interval
$E P H X 1$ activity. Interestingly the control group showed an excess of very slow phenotypes, but its frequency was low in both groups. In our analysis the slow activity variant of EPHX1 enzyme was associated with a significantly increased the risk for COPD. This result provides additional support to the notion that EPHX1 is likely to be involved in COPD pathogenesis.

Previous studies about the potent anti-inflammatory properties of the PPARG agonists suggest the use of $P P A R G$ ligands in COPD therapy $[12,30,31]$ and association of PPARG gene polymorphisms with the development of asthma has been reported [11]. These lines of evidence prompted us to investigate PPARG gene association existed between the presence of certain PPARG gene polymorphisms and COPD outcome. Using IHC staining and RT-QPCR measurements, we have confirmed PPARG mRNA and protein expression in lung tissues and particular in AM [32]. Although gene expression level is comparable in patients and healthy individuals, polymorphisms of the gene still could be potential candidate markers of the disease if a functionally altered PPARG has a role in the development in COPD.

Among the three SNPs we have genotyped in PPARG - rs1801282, rs3856806 and rs1800571 - the rs1800571 was excluded since all individuals carried an identical homozygous genotype [33]. Our single-marker tests for the other two coding variants yielded a significant association for the minor allele of His447His polymorphism in logistic regression adjusted for both SNPs, age, sex and pack-years $(\mathrm{OR}=1.853 ; 95 \% \mathrm{CI}=1.09-3.14 ; \mathrm{P}=$ $0.02)$. The His447His variant did not cause amino acid change and it has no known function. However, several papers pointed out that exonic synonymous SNPs can affect mRNA splicing or stability [34,35]. Any change in these processes could exert a significant effect on protein function, therefore there was a reason to investigate the association of this SNP with COPD. Of course the possibility, that the His447His SNP is tightly linked with an unknown functional variant that determine COPD susceptibility can not be excluded.

A modest pair-wise LD was found between rs1801282 and rs3856806. Since the use of SNP-based haplotypes 

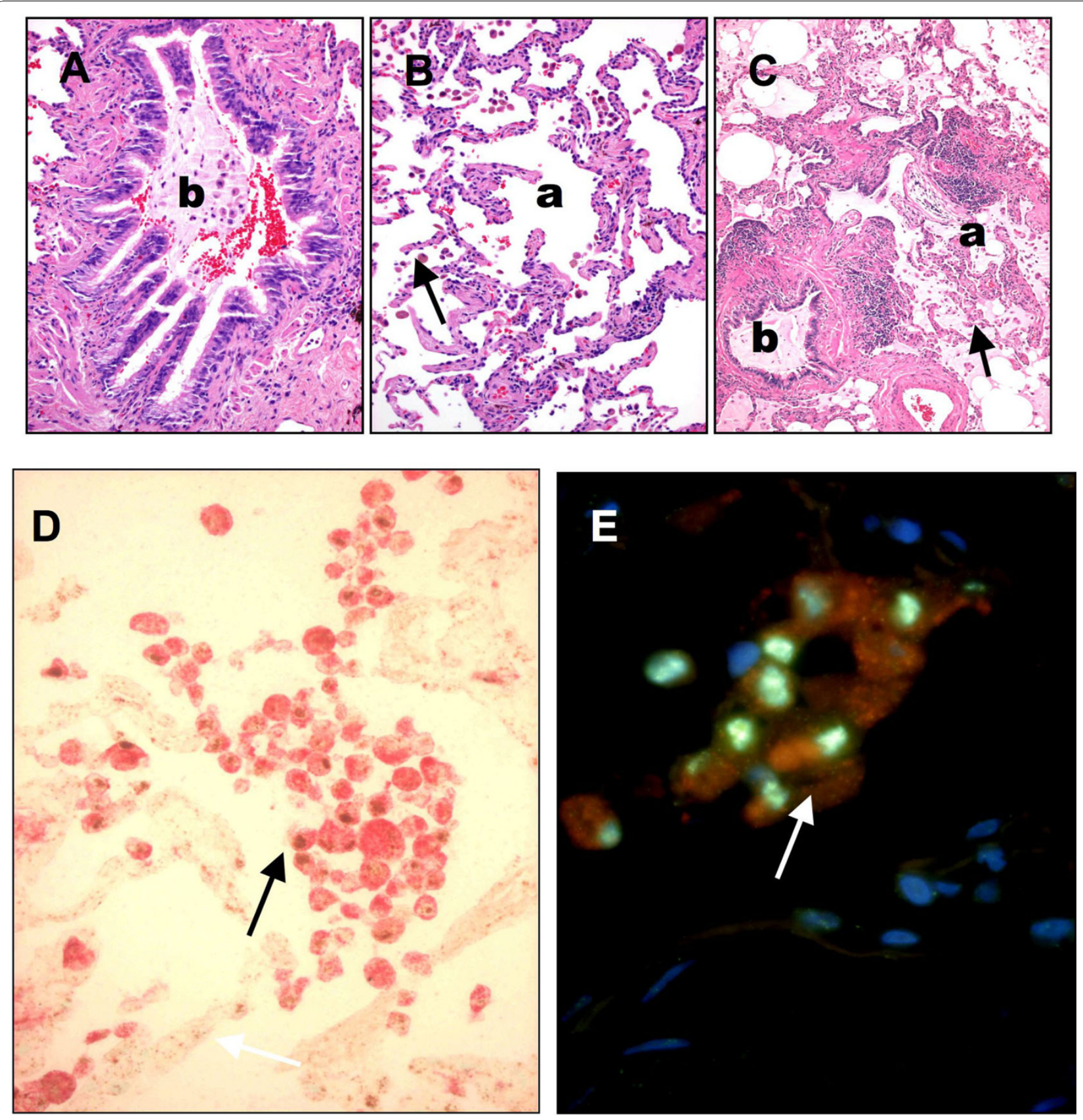

Figure 1 Morphology and immunohistochemistry of COPD-associated lung lesions. A: Chronic bronchitis. B: Centriacinar emphysema. C: Advanced active bronchitis with fibrosis and emphysema. $\boldsymbol{A}-\mathbf{C}$, hematoxylin-eosin staining; D: CD68-PPARG coexpression with double IHC staining using alkaline phosphatase [red cytoplasm-CD68] and diamino-benzidine [brown nuclei-PPARG]. E: Cells with red fluorescence and green nuclei DCSign-PPARG double fluorescence staining. Nuclear counter-staining is DAPI. Indications: b, bronchus; $\mathbf{a}$, alveolar spaces; arrows, alveolar macrophages. Original magnifications: A-D 20x; E 40X.

in genetic association studies may offer a more powerful approach than the use of individual SNPs, a haplotype analysis was also performed. A significant difference was found in the frequency of GC haplotype (containing the minor G allele of Pro12Ala and major C for His447His variant) between the control and COPD groups and the association of this haplotype to COPD outcome was also determined. The GC haplotype confers a significant lower risk for COPD, pointing to a potential functional protective effect of this haplotype.

Interestingly the minor allele of Pro12Ala polymorphism that lowers the binding affinity of PPARG protein to 


\section{hPPARG/hCyclophilin A}

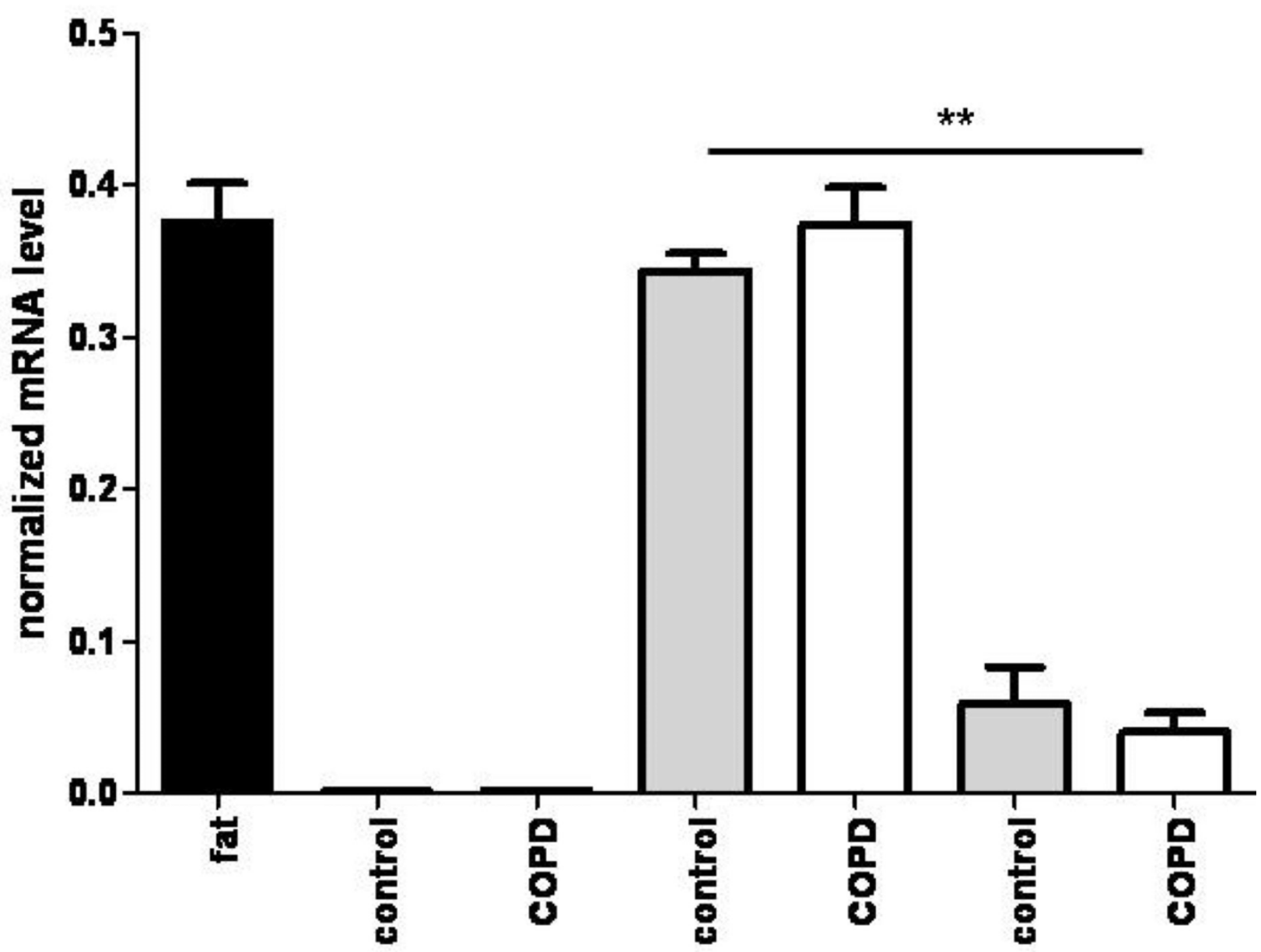

\section{peripheral blood alveolar monocyte macrophage \\ lung tissue}

Figure 2 mRNA expression of PPARG. PPARG showed as high as mRNA expression level in alveolar macrophages as in subcutan fat and also showed expression in the whole lung tissue with significantly lower level (Mann-Whitney $U$ test). However it was not expressed in peripheral blood monocytes. Data presented normalized values of RT-QPCR measurements; Cyclophilin A was used as housekeeping gene. Grey bars represent mean values of 5 control patients; white bars represent mean values of 5 COPD patients. ${ }^{* *} p<0.01$.

Table 4 Allele and genotype frequencies of examined PPARG gene polymorphisms

\begin{tabular}{|c|c|c|c|c|c|c|c|c|c|}
\hline \multirow[t]{2}{*}{ Gene Symbol } & \multirow{2}{*}{$\begin{array}{c}\text { SNP ID } \\
\text { rs1801282 (Pro12Ala) } \\
\end{array}$} & \multicolumn{2}{|c|}{ Allele frequency } & \multicolumn{3}{|c|}{ Genotype frequency } & \multirow{2}{*}{$\begin{array}{c}{ }^{\S} \text { Hardy-Weinberg Equilibrium } \\
\text { P value }\end{array}$} & \multicolumn{2}{|c|}{ Logistic Analysis } \\
\hline & & C & G & CC (\%) & CG (\%) & GG (\%) & & OR $(95 \% \mathrm{Cl})$ & \#P value \\
\hline Controls & & 0.864 & 0.136 & $217(75.2)$ & $64(22.4)$ & $7(2.4)$ & 0.398 & $0.68(0.40-1.14)$ & 0.15 \\
\hline Cases & & 0.874 & 0.126 & $199(76.2)$ & $67(22.3)$ & $4(1.5)$ & 0.869 & & \\
\hline & rs3856806 (His447His) & C & $T$ & CC (\%) & $\mathrm{CT}(\%)$ & $\Pi(\%)$ & $P$ value & OR $(95 \% \mathrm{Cl})$ & \#P value \\
\hline Controls & & 0.882 & 0.118 & $224(78.8)$ & $53(18.7)$ & $8(2.5)$ & 0.09 & $1.85(1.09-3.14)$ & 0.02 \\
\hline Cases & & 0.862 & 0.138 & $199(74.0)$ & $65(24.5)$ & $5(1.5)$ & 0.57 & & \\
\hline
\end{tabular}

${ }^{s} \chi^{2}$-test was used, OR: odds ratio, Cl: confidence interval

"Adjusted for age and pack-year 
Table 5 The distribution and strength of association of PPARG haplotypes

\begin{tabular}{ccccc}
\hline Haplotypes & COPD (freq.) & Control (freq.) & ${ }^{\text {s }}$ P value & OR $(\mathbf{9 5 \%} \mathbf{C l})$ \\
\hline CC & 0.834 & 0.832 & 0.914 & $1.02(0.74-1.40)$ \\
\hline CT & 0.039 & 0.030 & 0.424 & $1.31(0.68-2.50)$ \\
\hline GC & 0.028 & 0.053 & 0.035 & $0.51(0.27-0.96)$ \\
\hline GT & 0.098 & 0.085 & 0.429 & $1.18(0.78-1.77)$
\end{tabular}

${ }^{s} \chi^{2}$-test was used, OR: odds ratio, Cl: confidence interval

peroxisome proliferator response element was found to be associated with lower body mass index, improved insulin sensitivity, decreased risk of type 2 diabetes $[36,37]$ and reduced risk to develop colorectal cancer [38]. Higher frequency of $\mathrm{T}$ allele of the His447His C/T polymorphism was observed in colon cancer $[39,40]$.

We are aware of the fact that significant results could prove to be false positives, and a clear limitation of our study is the relatively low sample size. The study has other limitations such as that population stratification should be investigated in these kinds of studies and we did not analyze a second cohort to replicate our results. Possible gene-gene and geneenvironment interactions pose a difficulty for genetic analysis of COPD association studies, too. Further studies using larger populations are needed and other variants in the PPARG gene should be investigated in order to clarify the association of PPARG and individual susceptibility to the development of COPD.

\section{Conclusions}

In summary, our study provided support for the suggested causative role of EPHX1 polymorphisms and phenotypes imputed from exon 3 and exon 4 genotype data in COPD outcome in a Hungarian population.

We have carried out the first investigation of PPARG gene polymorphisms in a case-control COPD study and characterized the association between individual SNPs and haplotypes in PPARG and susceptibility to COPD. Although the GC haplotype has a modest protective effect, it might point toward the potential importance of common alleles with weak effect in heterogeneous diseases, like COPD. The documentation of PPARG haplotype association with COPD identifies this important gene as a target of further investigation for the pathogenesis of COPD and as a potential target of therapy.

\section{Additional material}

Additional File 1: Table S1. Characteristics of tested SNP

Characteristics, NCBI reference numbers and $A B I$ assays code of

examined single nucleotide polymorphisms.

\section{Abbreviations}

COPD: chronic obstructive pulmonary disease; EPHX1: microsomal epoxide hydrolase; FEV1: forced expiratory volume in one second; FVC: forced vital capacity; PPARG: peroxisome proliferator-activated receptor gamma.

\section{Acknowledgements}

The authors are indebted to Zsuzsa Bodnár for clinical coordination, Dr Attila Vaskó, Dr Péter Szabó, Dr Sándor Sz. Kiss, Titanilla Tölgyesi, Mária Ráduly, for the help with clinical sample collection. The authors would like to thank the expert technical assistance of Júlia Buslig, Ibolya Fürtös and Marta Béládi. This work was supported by grants from the Hungarian National Office for Research and Technology (NKFP 1/007/01, NKFP 1A/008/04), Hungarian grant for the National Research Fund (NI 67877 and TAMOP-4.2.2/08/1).

\section{Author details}

'Department of Human Genetics, University of Debrecen, Debrecen, Hungary. ' Department of Biochemistry and Molecular Biology, Research Center for Molecular Medicine, University of Debrecen, Debrecen, Hungary. ${ }^{3}$ Clinical Genomics Center, Medical and Health Science Center, Research Center for Molecular Medicine, University of Debrecen, Debrecen, Hungary. ${ }^{4}$ Apoptosis and Genomics Research Group of the Hungarian Academy of Sciences, Research Center for Molecular Medicine, University of Debrecen, Debrecen, Hungary. ${ }^{5}$ Department of Pulmonology, Medical and Health Science Center, University of Debrecen, Debrecen, Hungary. ${ }^{6}$ Department of Pathology, University of Debrecen, Medical and Health Science Center, Debrecen, Hungary. ${ }^{7}$ Pfizer Global Research and Development, Sandwich, UK. ${ }^{8}$ Biosystems International SAS, Evry, France. ${ }^{9}$ Department of Pulmonology, Semmelweis Health Care Center of Miskolc, Miskolc, Hungary.

\section{Authors' contributions}

LN is an International Scholar of HHMI and holds a Wellcome Trust Senior Research Fellowship in Biomedical Sciences, he planned and directed the study. AP performed data analyses and prepared the manuscript. SP performed the genotyping measurements and RT-QPCR analyses and prepared figures and tables. ECs organized patient recruitment and sample collection. BS organized sample preparation. BD performed IHC staining. IS performed data analyses. IK and LT participated in the planning and the design of the study and helped prepare the manuscript.

All authors have read and approved the final version of the manuscript.

\section{Competing interests}

LN has no conflicts of interests (COIs) to disclose. AP has no COls to disclose. SP has no COls to disclose. ECs has no COls to disclose. BS has no COls to disclose. BD has no COls to disclose. IS has no COls to disclose. IK is director of Pfizer and holder of Pfizer stock. LT has no COls to disclose.

Received: 10 May 2010 Accepted: 2 November 2010 Published: 2 November 2010

\section{References}

1. Sandford AJ, Silverman EK: Chronic obstructive pulmonary disease. 1: Susceptibility factors for COPD the genotype-environment interaction. Thorax 2002, 57(8):736-741.

2. Seifart C, Plagens A: Genetics of chronic obstructive pulmonary disease. Int J Chron Obstruct Pulmon Dis 2007, 2(4):541-550.

3. Joos L, Pare PD, Sandford AJ: Genetic risk factors of chronic obstructive pulmonary disease. Swiss Med Wkly 2002, 132(3-4):27-37.

4. Sandford AJ, Joos L, Pare PD: Genetic risk factors for chronic obstructive pulmonary disease. Curr Opin Pulm Med 2002, 8(2):87-94.

5. Molfino NA: Genetics of COPD. Chest 2004, 125(5):1929-1940.

6. Hersh CP, DeMeo DL, Silverman EK: National Emphysema Treatment Trial state of the art: genetics of emphysema. Proc Am Thorac Soc 2008, 5(4):486-493.

7. Hersh CP, Demeo DL, Lange C, Litonjua AA, Reilly JJ, Kwiatkowski D, Laird N, Sylvia JS, Sparrow D, Speizer FE: Attempted replication of reported chronic obstructive pulmonary disease candidate gene associations. Am J Respir Cell Mol Biol 2005, 33(1):71-78.

8. Szatmari I, Nagy L: Nuclear receptor signalling in dendritic cells connects lipids, the genome and immune function. EMBO J 2008, 27(18):2353-2362. 
9. Asada K, Sasaki S, Suda T, Chida K, Nakamura H: Antiinflammatory roles of peroxisome proliferator-activated receptor gamma in human alveolar macrophages. Am J Respir Crit Care Med 2004, 169(2):195-200.

10. Spears M, MCSharry C, Thomson NC: Peroxisome proliferator-activated receptor-gamma agonists as potential anti-inflammatory agents in asthma and chronic obstructive pulmonary disease. Clin Exp Allergy 2006, 36(12):1494-1504.

11. Oh SH, Park SM, Lee YH, Cha JY, Lee JY, Shin EK, Park JS, Park BL, Shin HD, Park CS: Association of peroxisome proliferator-activated receptorgamma gene polymorphisms with the development of asthma. Respir Med 2009, 103(7):1020-1024.

12. Standiford TJ, Keshamouni VG, Reddy RC: Peroxisome proliferatoractivated receptor-\{gamma\} as a regulator of lung inflammation and repair. Proc Am Thorac Soc 2005, 2(3):226-231.

13. Kiyohara C, Yoshimasu K, Takayama K, Nakanishi Y: EPHX1 polymorphisms and the risk of lung cancer: a HuGE review. Epidemiology 2006, 17(1):89-99

14. Hersh CP, Demeo DL, Lazarus R, Celedon JC, Raby BA, Benditt JO, Criner G, Make B, Martinez FJ, Scanlon PD: Genetic association analysis of functional impairment in chronic obstructive pulmonary disease. Am J Respir Crit Care Med 2006, 173(9):977-984.

15. Hersh CP, DeMeo DL, Reilly JJ, Silverman EK: Xenobiotic metabolizing enzyme gene polymorphisms predict response to lung volume reduction surgery. Respir Res 2007, 8:59.

16. Brogger J, Steen VM, Eiken HG, Gulsvik A, Bakke P: Genetic association between COPD and polymorphisms in TNF, ADRB2 and EPHX1. Eur Respir J 2006, 27(4):682-688.

17. Chappell S, Daly L, Morgan K, Guetta-Baranes T, Roca J, Rabinovich R, Lotya J, Millar AB, Donnelly SC, Keatings V: Genetic variants of microsomal epoxide hydrolase and glutamate-cysteine ligase in COPD. Eur Respir J 2008, 32(4):931-937.

18. Hurd S: The impact of COPD on lung health worldwide: epidemiology and incidence. Chest 2000, 117(2 Suppl):1S-4S.

19. Szatmari I, Gogolak P, Im JS, Dezso B, Rajnavolgyi E, Nagy L: Activation of PPARgamma specifies a dendritic cell subtype capable of enhanced induction of iNKT cell expansion. Immunity 2004, 21(1):95-106.

20. Tsakiris I, Soos G, Nemes Z, Kiss SS, Andras C, Szanto J, Dezso B: The presence of carboxypeptidase-M in tumour cells signifies epidermal growth factor receptor expression in lung adenocarcinomas: the coexistence predicts a poor prognosis regardless of EGFR levels. J Cancer Res Clin Oncol 2008, 134(4):439-451.

21. Gogolak P, Rethi B, Szatmari I, Lanyi A, Dezso B, Nagy L, Rajnavolgyi E: Differentiation of CD1a- and CD1a+ monocyte-derived dendritic cells is biased by lipid environment and PPARgamma. Blood 2007, 109(2):643-652.

22. Chiano MN, Clayton DG: Genotypic relative risks under ordered restriction. Genet Epidemiol 1998, 15(2):135-146.

23. Shi YY, He L: SHEsis, a powerful software platform for analyses of linkage disequilibrium, haplotype construction, and genetic association at polymorphism loci. Cell Res 2005, 15(2):97-98.

24. Li Z, Zhang Z, He Z, Tang W, Li T, Zeng Z, He L, Shi Y: A partition-ligationcombination-subdivision EM algorithm for haplotype inference with multiallelic markers: update of the SHEsis [http://analysis.bio-x.cn]. Cell Res 2009, 19(4):519-523.

25. Smith CA, Harrison DJ: Association between polymorphism in gene for microsomal epoxide hydrolase and susceptibility to emphysema. Lancet 1997, 350(9078):630-633.

26. Benhamou S, Reinikainen M, Bouchardy C, Dayer P, Hirvonen A: Association between lung cancer and microsomal epoxide hydrolase genotypes. Cancer Res 1998, 58(23):5291-5293.

27. Huang TH, Razmovski-Naumovski V, Kota BP, Lin DS, Roufogalis BD: The pathophysiological function of peroxisome proliferator-activated receptor-gamma in lung-related diseases. Respir Res 2005, 6:102.

28. Belvisi MG, Hele DJ, Birrell MA: Peroxisome proliferator-activated receptor gamma agonists as therapy for chronic airway inflammation. Eur $\rfloor$ Pharmacol 2006, 533(1-3):101-109.

29. Omiecinski CJ, Hassett C, Hosagrahara V: Epoxide hydrolasepolymorphism and role in toxicology. Toxicol Lett 2000, 112-113:365-370

30. Caito S, Yang SR, Kode A, Edirisinghe I, Rajendrasozhan S, Phipps RP, Rahman I: Rosiglitazone and 15-deoxy-Delta12,14-prostaglandin J2, PPARgamma agonists, differentially regulate cigarette smoke-mediated pro-inflammatory cytokine release in monocytes/macrophages. Antioxid Redox Signal 2008, 10(2):253-260.

31. Patel HJ, Belvisi MG, Bishop-Bailey D, Yacoub MH, Mitchell JA: Activation of peroxisome proliferator-activated receptors in human airway smooth muscle cells has a superior anti-inflammatory profile to corticosteroids: relevance for chronic obstructive pulmonary disease therapy. I Immunol 2003, 170(5):2663-2669.

32. Reddy RC: Immunomodulatory role of PPAR-gamma in alveolar macrophages. J Investig Med 2008, 56(2):522-527.

33. Ristow M, Muller-Wieland D, Pfeiffer A, Krone W, Kahn CR: Obesity associated with a mutation in a genetic regulator of adipocyte differentiation. N Engl J Med 1998, 339(14):953-959.

34. Capon F, Allen MH, Ameen M, Burden AD, Tillman D, Barker JN, Trembath RC: A synonymous SNP of the corneodesmosin gene leads to increased mRNA stability and demonstrates association with psoriasis across diverse ethnic groups. Hum Mol Genet 2004, 13(20):2361-2368.

35. Sauna ZE, Kimchi-Sarfaty C, Ambudkar SV, Gottesman MM: Silent polymorphisms speak: how they affect pharmacogenomics and the treatment of cancer. Cancer Res 2007, 67(20):9609-9612.

36. Deeb SS, Fajas L, Nemoto M, Pihlajamaki J, Mykkanen L, Kuusisto J, Laakso M, Fujimoto W, Auwerx J: A Pro12Ala substitution in PPARgamma2 associated with decreased receptor activity, lower body mass index and improved insulin sensitivity. Nat Genet 1998, 20(3):284-287.

37. Altshuler $\mathrm{D}$, Hirschhorn JN, Klannemark M, Lindgren CM, Vohl MC Nemesh J, Lane CR, Schaffner SF, Bolk S, Brewer C: The common PPARgamma Pro12Ala polymorphism is associated with decreased risk of type 2 diabetes. Nat Genet 2000, 26(1):76-80.

38. Landi S, Moreno V, Gioia-Patricola L, Guino E, Navarro M, de Oca J, Capella G, Canzian F: Association of common polymorphisms in inflammatory genes interleukin (IL)6, IL8, tumor necrosis factor alpha, NFKB1, and peroxisome proliferator-activated receptor gamma with colorectal cancer. Cancer Res 2003, 63(13):3560-3566.

39. Jiang J, Gajalakshmi V, Wang J, Kuriki K, Suzuki S, Nakamura S, Akasaka S, Ishikawa H, Tokudome S: Influence of the C161T but not Pro12Ala polymorphism in the peroxisome proliferator-activated receptor-gamma on colorectal cancer in an Indian population. Cancer Sci 2005, 96(8):507-512.

40. Siezen $\mathrm{CL}$, van Leeuwen $\mathrm{Al}$, Kram NR, Luken ME, van Kranen $\mathrm{HJ}$, Kampman E: Colorectal adenoma risk is modified by the interplay between polymorphisms in arachidonic acid pathway genes and fish consumption. Carcinogenesis 2005, 26(2):449-457.

\section{Pre-publication history}

The pre-publication history for this paper can be accessed here: http://www.biomedcentral.com/1471-2350/11/152/prepub

\section{doi:10.1186/1471-2350-11-152}

Cite this article as: Penyige et al:: Analyses of association between PPAR gamma and EPHX1 polymorphisms and susceptibility to COPD in a Hungarian cohort, a case-control study. BMC Medical Genetics 2010 11:152.

\section{Submit your next manuscript to BioMed Central and take full advantage of:}

- Convenient online submission

- Thorough peer review

- No space constraints or color figure charges

- Immediate publication on acceptance

- Inclusion in PubMed, CAS, Scopus and Google Scholar

- Research which is freely available for redistribution 